these must be postponed till further observations have been made, but I am inclined to consider it a distinct species. Dr. St. Clair Symmers ${ }^{1}$ has also described a liquefying fluorescent bacillus, but, as he gives no details of its biological characters, it is impossible to say whether it is identical with my organism or not.

IV.-Bacillus Luteus Liquefaciens,

obtained from the inner surface of the prepuce

Morphology.-Short thick rods with rounded ends, usually constricted in the middle, occasionally forming short chains or longer unjointed rods.

Biology.-Gelatine cultures: on plates in two days the colonies appear as fine, round, slightly-yellowish points. In four days the superficial colonies are pale yellow, hemispherical, smooth, shining and opaque, about 1 millimetre in diameter. The organism commences to liquefy the gelatine in seven or eight days, the colonies becoming surrounded by a sharply-defined area of clear liquefied gelatine. The deep colonies are of irregular shape, brownish-yellow, and granular Stroke cultures are yellowish-white, with finely-toothed edges, gradually become bright yellow, and liquefy in eight to ten days. In stab cultures there is a flat growth on the surface with a fine concentric arrangement, whitish veil in the depth. On agar-agar it grows well at ordinary temperatures, but not at a higher temperature than $28^{\circ} \mathrm{C}$.; it forms a slimy yellowish-white growth. On potato, thrives with difficulty.

Remarks. - No free spores have been observed, hut some preparations show signs of doubtful sporulation. The organism does nos grow at blood heat.

\section{V.-Staphylococcus Flavescens,}

obtained from the toes, cruro-scrotal region, and prepuce. It may possibly be the micrococcus flavescens incompletely described by Cornil and Babes in their textbook. ${ }^{2}$

Morphology.-Round or oval micrococci of varying size arranged irregularly in groups.

Biology.-Gelatine cultivations vary very much in colour and rapidity of growth, sometimes forming a wrinkled layer. sinking in the liquefied gelatine, sometimes forming isolated pasty-looking masses; in the latter case liquefaction appears to be more extensive and rapid ; these variations are probably due to slight variations in the nutrient media. Liquefaction begins in three to six days, and there is always a flaky deposit at the bottom. In puncture cultivations, growth is slower; it begins at the surface as a pale zellow growth, and slowly extends into the depths, where isolated yellowish colonies may be seen. In plate cultivations the colonies begin to appear in three or four days; they are round, yellow, and granular, and have sharply defined edges which may be irregular. Liquefaction begins about the fifth or sixth day. On agar it grows rapidly as a thin film of dirty yellowish-white colour with scalloped edges. On potato it forms a dry, lustreless, dirty grey streak, limited to the needle track. Sown in broth, the fluid becomes turbid after two hours in the incubator, and after a few days forms a thin yellowish pellicle.

\section{VI.-Micrococcus Flavescens Subsidens.}

Morphology.-Medium-sized round micrococci arranged irregularly in groups, occasionally in short chains of four to six elements.

Biology.-In gelatine cultivations the organism forms a pale creamy yellow growth, flat and shining, with smooth regular edges; in about ten days a gradual subsidence of the growth takes place without liquefaction; cultures are extremely viscid and tenacious. On plates there are yellowish or creamy, shining, round colonies, which with the microscope are seen to be finely granular and of a brownish yellow colour. The deep colonies are dark brown, the superficial more translucent, gradually becoming yellow. Stav cultures show a creamy zellow growth about t-inch in diameter, which gradually sinks in the gelatine without liquefaction, forming a cylindrical depression up to $\frac{1}{2}$-inch or more in depth; at no time is fluid gelatine observed. On agar-agar it grows slowly in the form of a thin, dirty white film, with rounded edges.

In conclusion, I desire to express my thanks to Dr. Curnow, of King's College Hospital, for permission to obtain my material from his patients, and to Professor Crookshank for his kind help and suggestions during my experiments.

\section{NOTES ON A CASE OF MILKY ASCITIC FLUID:1}

By G. NIEUWONDT, M.B., C.M., M.R.C.S., AND

R. H. ROZENZWEIG, M.B., C.M.

ON May 24th, 1889, I was called to see A. D., aged 15 months, a thin and weakly child, suffering from diarrhœe and vomiting. She had recovered from these symptoms on May 30th but on the night of June 10th she became restless and seemed to be in pain. When seen on June 11th the abdomen was distended with tympanites and very tender, pulse rapid and wiry, and temperature above normal. Under treatment the abdomen had become all but normal on June 16th. The same symptoms then returned. By June 20th the symptoms were less acute, but she continued to perspire copiously, and I thought I could detect dulness low down in the abdomen. On June 28 th the same symptoms reappeared. The distension of the abdomen on each occasion was greater that on the previous one.

Dr. Loubser was now called in consultation. We found the abdomen distended, and so tender as hardly to allow of even gentle percussion. The distension was chiefly due to tympanites, but there was some fluid below the umbilicus; The pulse small and rapid, temperature $102^{\circ} \mathrm{F}$., perspiration copious, bowels loose (two to four times in twenty-four hours). We came to the conclusion that it was a case of chronic peritonitis with subacute exacerbations, possibly a case of tabes mesenterica. The symptoms slowly increased in spite of treatment with mercurial and other remedies.

The treatment mainly consisted of inunction of the abdomen with mercurial ointment and extract of belladonna equal parts, rags dipped in cod-liver oil being laid over the abdomen whenever there was too much irritation to continue the ointment, and malt and cod-liver oil internally.

About September 1st the tenderness of the abdomen was increased, the fluid had risen well above the umbilicus, and the abdomen was so distended as to bulge out below the costal cartilages in front and to be visible in the flanks from behind. The pulse was intermittent and the child cyanosed. I advised aspiration, and Dr. Rozenzweig was called in consultation on September 5 th. We aspirated midway between the pubes and umbilicus, and drew off 20 ounces of white milky fluid. Being afraid of collapse, we stopped there, though there was still a large amount present. Some of this fluid was sent to Dr. Herman, President of the Cape of Good Hope Branch of the British Medical Association, and to Dr. Anderson and one or two other medical men in Cape Town.

The fluid had the appearance of rich creamy milk; specific gravity 1022. It did not coagulate spontaneously on standing. it contained a large amount of albumen and fat. Under the microscope it showed a granular basis with large nucleated cells here and there. The abdomen was still too distended to permit a satisfactory examination. No enlarged glands or any other abnormality were detected.

The fluid recommenced rising at once, and on September 9th I aspirated again and drew off 40 ounces, once more leaving some fluid behind, but on September 16th I completely emptied the abdomen of fluid, obtaining 80 ounces. As the abdominal walls were very flaccid and the tenderness not great, I examined the parts carefully, but could detect nothing abnormal. On September 24th the abdomen was more distended than it had ever been before, and I now obtained 90 ounces of fluid. All this time the child was thin and anxious-looking, fretful, and perspiring copiously; still, when not distressed with flatus, its appetite was fairly good, and the bowels loose, but never more than three or four times in twenty-four hours. On September 29 th the abdomen was aspirated once more, yielding 55 ounces, but was not emptied owing to the cannula getting obstructed. On October 4th I drew off 90 ounces, on October 10th 50 ounces, on October 14th 70 ounces, and on October 20 th again 70 ounces. On October $26 \mathrm{th}$ an attack of diarrhoea intervened, but at once yielded to calomel, chalk, and opium. On October 28th I aspirated again, getting 60 ounces, which was relatively less than on any previous occasion. On November 5th I got 55 ounces.

1 Read before the Cape of Good Hope Branch of the British Medical

* Cornil et Babes, Les Bactéries, Paris, 1891. Association. 
On November 9th another attack of diarrhœa came on, but also soon passed over. On November 14th the fluid had not much increased, and all the symptoms were improved. On November 18th the diarrhœa : was repeated, but the fluid had now diminished. The inunction with mercury and belladonna was continued, as well as the extract of malt and codliver oil. The child now began to gain flesh, and by January was quite as strong and healthy as before, and in another six months she was strong and plump, above the average child of her age, nor has she had any other serious ailment since then. In two months' time she had been aspirated eleven times and 680 ounces of fluid had been taken from her.

Remarks by Dr. Rozenzweig.-The fluid was of a dense consistence, closely resembling milk in colour and appearance, specific gravity 1022 , reaction neutral, of a faintlysweetish odour. There was : no spontaneous coagulation, nor was there any pinkish discoloration, even after an interval of four or five days. With heat a heavy coagulum formed; on the addition of cold nitric acid a white precipitate formed which, on being heated, changed to yellow. Caustic potash increased the fluidity. Microscopical examination showed tinely-granular matrix, with large nucleated cells interspersed, bearing, therefore, on the whole, but slight resemblance to the generally accepted characters of chyle.

The literature of chylous ascitic fluid is scanty. The most complete monograph on the subject is one by Dr. Busey, $r$ ad before the New York Medical Association, in which he chronicles a series of thirty-three cases, and where the causation is ascribed to (1) an obstruction to the flow of chyle thr iugh the lacteals, receptaculum chyli, or thoracic duct, imp 'ding its exit into the left subclavian vein, or retarding the current of blood in that vein, right heart, or lesser circulation; (2) filariæ; (3) tuberculous and puerperal conditions. It does not appear that in all these cases the fluid was taken to be other than chyle, but in the case just recorded the physical characters of the fluid did not correspond to those of chyle. There was no spontaneous coagulation, no pinkish discoloration, and the specific gravity was higher. It is exceedingly difficulty to obtain pure chyle, mixed, as it is, with lymph in the thoracic duct and receptaculum, and it has been stated that chyle drawn immediately from the intestine does not coagulate.

The recovery of the child after removal of such an enormous quantity of fluid (680 ozs., or $42 \frac{1}{2}$ lbs.--more than double the weight of the child) is an additional argument against the chylous nature of the fluid in the present case. If filariæ had been the cause, one would naturally have expected that at some period or other of the child's illness chyluria would have made its appearance, but such was not the case, and to the best of my knowledge no case of filariæ has yet been recorded in the colony.

Mr. Pearce Gould has recorded a case of hydrocele, in which a clear straw-coloured fluid was withdrawn, and which, at the end of the operation, became thick like pea soup, and on standing separated into a clear lower stratum of greenishyellow colour, and an upper, opaque, yellow, cream-like layer, consisting of fine fat granules with oil drops. He also mentions a case recorded by Vidal de Cassis of double , hydrocele, where the fluid was like milk in appearance; a similar case recorded by Fergusson, in which the fluid, of an alkaline reaction and specific gravity 1019 , was shown to be hydrocele fluid with the addition of free fat; and another case recorded by Shattock, in which the milky fluid was attributed to obstruction or rupture, or both, of the lymphatics. M. Letulle ${ }^{2}$ gives a case of milky ascitic fluid, following on an attack of diarrhœa with peritonitis, with postmortem evidences of tubercle, and holds that a chronic inflammatory element is a potential factor in the production of such fluids. Klebs ascribes the production of such milky fluids to fatty degeneration of the endothelium of the tunica in hydrocele. It seems strange that in all these cases no post-mortem traces of ruptured lymphatics, thoracic ducts, or receptacula have been discovered, and that in the very disease which claims for its pathology obstructed or ruptured lymphaticselephantiasis arabum-few, if any, recorded cases are found of milky ascitic fluid.

If, then, an inflammatory element is concerned in the pro- duction of a white hydrocele fluid, why should not the same obtain in the peritoneal cavity? The difference would only be one of degree. Cannot Mr. Gould's case be taken as a transitional stage between the clear and the milky hydrocele fluid? Peritonitic fluid, like hydrocele fluid, contains a small amount of fat, and although the circumstances under which clear fluid is produced in one instance and a milky fluid in another are undetermined, one might safely attribute the large amount of fat granules in the case just recorded as due to the greatly increased degenerative action in the peritoneum. It is clear from the clinical history, that after a varying period of ill health the child had three distinct peritonitic attacks on June 11th, June 17th, and June 28th, before the last of which fluid was for the first time detected.

\section{REMARKS ON}

\section{TWO CASES OF INSANITY CAUSED BY} INHALATION OF SULPHURETTED HYDROGEN.

BY J. WIGLESWORTH, M.D.LoND., M.R.C.P., Medical Superintendent, Rainhill Asylum; Lecturer on Mental Diseases University College, Liverpool.

Case I.-B. H., aged 30, was admitted into Rainhill Asylum, September 20th, 1888. There was no history of insanity in the family. The patient himself was said never to have had any illness, but he appears to have drunk somewhat. He was a single man and a labourer in some chemical works. On the morning previous to his admission into the asylum he went to his work as usual. About 9 A.M. he was observed to be acting strangely, throwing his arms about wildly and shouting. In addition he lost power over his legs. As he was engaged in an occupation which exposed him to some chemical fumes (probably sulphuretted hydrogen) it was supposedapparently with very good reason-that he had inhaled the gas. He remained excited and rough all that day, laughing and shouting by turns, and did not appear to recognise his brother. When admitted into the asylum on the following day he was in a very maniacal condition, shouting and throwing himself about, and it took several men to carry him to the ward. He kept throwing his arms about, but was distinctly unsteady on his legs when made to stand. In bed he wriggled about throwing his head back on the pillow, and waving his right arm round and round. This condition of things lasted for two or three days, when he became more quiet; and he then gradually passed into a taciturn, depressed state, sitting or standing about for hours doing nothing, and never speaking except when addressed. After remaining in this condition for many months he gradually developed delusions of persecution and interference, and became very dangerous, making assaults on those around him. This condition of things lasted for upwards of a year; but during the last few months an improvement has set in, and at the present time, although apparently not altogether free from delusions, these are nevertheless much less prominent; and though still excitable and talkative, he is much more tractable, and is regularly employed at outside labour. It is improbable, however, that he will ever fully recover.

CASE II.--R. H., aged 32, was admitted into Rainhill Asylum on January 27 th, 1890 . He was a married man with three children, and was employed as an engineman at some chemical works. He had always been healthy and temperate, but shortly before the onset of the mental affection he had had an attack of bronchitis, which kept him at home for about ten days. Whilst at his work a few days after this he accidentally inhaled sulphuretted hydrogen and became "gassed," as it is called at the chemical works. This produced headache, stupor, and prostration, for which he was kept at home for a few days, when he became delirious. He passed rapidly into a very violent excited state, shouting and gesticulating; said he was Jesus Christ, etc.; tried to bury his head in the floor, and to raise his feet above his head. When admitted into the asylum, three days later, he was still very violent and excited, gesticulating and talking incoherently chiefly on religious subjects. He continued in a maniacal condition for two or three weeks, but at the end of a month from admis- 